\title{
PREDATION THROUGH IMPALEMENT OF PREY: THE FORAGING BEHAVIOR OF DORYONYCHUS RAPTOR (ARANEAE, TETRAGNATHIDAE)
}

\author{
By Rosemary G. GILLESPIE \\ Department of Zoology and \\ Hawaiian Evolutionary Biology Program, \\ University of Hawaii, \\ Honolulu, HI 96822
}

\section{INTRODUCTION}

Specialized methods of predation are known to occur among a diverse array of spiders. Several web-building species, for example, have tailored their web for capture of specific prey, such as the ladder webs of certain araneids designed for capturing moths (Stowe 1978, Robinson 1982). A large number of web-building groups contain species that have secondarily abandoned webbuilding, this generally being associated with specialization in foraging behavior. Among theridiids, for example, it has occurred in Euryopis funebris, which remains sedentary in a highly localized microhabitat containing predictably abundant prey that can readily be detected by direct contact (Carico 1978). Additional examples can be found among the moth attracting araneids, some of which make a "bolas" line tipped with viscid glue and used for capturing prey (Stowe 1986). Others (e.g. the genus Kaira) spin no web at all, instead hanging upside down from a leaf, legs outstretched, waiting for insects to pass: Moths are captured in the outstretched legs of the spider, and then immobilized and wrapped. Among tetragnathids, abandonment of web-building is associated with the development of long spines on the legs (Gillespie 1991, 1992). Similar modifications are found in the araneid genera Arcys, Archemorus and Neoarchemorus (D. Clyne, pers. comm.).

One of the most remarkable morphological specializations found in spiders is an immense and unequal elongation of the tarsal claws (Forster et al. 1987). This type of morphological modification was initially described in Doryonychus raptor Simon

Manuscript received 24 May 1991 
(Araneae, Tetragnathidae). D. raptor was placed in the monospecific genus Doryonychus by Simon (1900) on the basis of the unique leg structure: The tarsal segments of the first two pairs of legs have a robust onychium (pretarsal process) and are lined with stout macrotricheae. The tips of the tarsi of the same legs are armed with strongly dissimilar claws, the prolateral claws being extremely long. Similar modifications have since been documented in widely disparate families of spiders: the Gradungulidae (Forster et al. 1987), the genus Hetrogriffus in the family Thomisidae (Platnick 1976) and, to a lesser extent the genus Celaenia in the Araneidae (Forster and Gray 1979). Little is known regarding the function of the long claws and associated features of the tarsal segments in these spiders although it appears often, but not always, to be associated with abandonment of web-building (Forster et al. 1987, Stowe 1986).

The present study examined the remarkable claw elongation in the Hawaiian tetragnathid D. raptor and whether it was associated with ecological, and/or behavioral modifications. The family Tetragnathidae as a whole is well-known worldwide for its ecological and behavioral homogeneity, with members building complete orb webs, usually over or near water (Wiehle 1963, Yoshida 1987). Their diet generally consists of small dipterans (Dabrowska Prot and Luczak 1968 a \& b, Dabrowska Prot et al. 1968, Gillespie i 986 , Gillespie 1987, Levi 1981). I examined the extent, if any, to which $D$. raptor had deviated from this pattern. I focused primarily on the foraging strategy of the species, through combined field and laboratory studies. I went on to associate behavioral modifications with structural features of the legs and spinneret spigot morphology.

\section{METHODS}

Distribution: D. raptor has been known to occur on the Hawaiian island of Kauai since the beginning of the century (Simon 1900), but there was no documentation as to where on this island it might be found. Its distribution was surveyed by collecting at sites throughout the island: (1) In high elevation wet forest in the Alakai swamp (1158 m) and Pihea trail (1158 m), the Mohihi Ditch (1067 $\mathrm{m})$ and along the Mohihi-Waialae trail to the Koaie Stream at various sites $(1120-1220 \mathrm{~m})$. (2) In mid elevation mesic forest in the 
Kuia Natural Area Reserve (320-1000 m). (3) In low elevation wet/mesic forest at Keahua (east Kauai at $305 \mathrm{~m}$ ), Wahiawa Bog (south Kauai at $646 \mathrm{~m}$ ), and the Waiahuakua Valley (north Kauai at $390 \mathrm{~m}$ ). Each site was surveyed once during the summer (July) and once during the winter (February). Surveys were conducted prior to dusk and after nightfall using a headlamp. In order to assess their abundance at a site, I conducted timed samples (collecting and counting all spiders observed over a 1-hour period) in addition to general collecting. This allowed determination of seasonality and comparison between sites.

Ecological affinities: Where the spiders were found, their activity and the substrate from which they were collected were noted.

Foraging Behavior: Observations were made in the field during periods of both rest and activity of the spiders. Focal animals were selected $(n=16)$ and observed for a 10 -minute period prior to being collected and taken back to the laboratory for further observations.

Laboratory experiments were conducted by maintaining 10 spiders individually in glass cages $(22 \times 22 \times 26 \mathrm{~cm})$ and feeding them drosophilids of different sizes. Twenty flies of one species were added to each cage, and the spiders observed for a 2-hour period over the subsequent three nights. Flies were then removed over the next three days, before repeating the study with a different fly species. The flies used were $D$. simulans $(1.8-2.2 \mathrm{~mm}), D$. grimashawi (4.5-5.5 $\mathrm{mm})$ and D. oahuensis $(6.5-7.4 \mathrm{~mm})$.

Motility on silk: I tested the ability of $D$. raptor to move around on silk threads by maintaining individuals in a cage for 7 days. Each day, the spider was gently touched, and observed as to whether it moved along prelaid silk threads.

Morphology: The structure of the legs was investigated by examining 3 males, 3 females and 3 first instar immatures, using a dissecting microscope and camera lucida attachment. Scanning electron microscopy was also conducted on the tarsal segments of both legs, in addition to the spinnerets, of a single individual female. The live spider was boiled in water for 40 secs in order to 
cause the spinneret spigots to evert. The spinnerets were then cut from the body, as were the 2 right front legs. These structures were then placed in plastic capsules with the central portion removed and nylon mesh placed inside the capsule (to allow exchange alcohol and $\mathrm{CO}_{2}$, while retaining the specimen). Filled capsules were put through an alcohol series (70\%, 85\%, 95\% and pure ethanol), then dried with an Autosamori-810 Critical Point Dryer. The structures were then removed from the capsules, mounted on stubs and sputtered with gold. Specimens were viewed using a Hitachi S-800 scanning electron microscope.

Development: In order to determine at what stage during development the spiders underwent extension of the tarsal claw, spiderlings had to be observed at very early instars. Mature females were maintained in the laboratory, and allowed to lay egg sacs. The egg sacs were subsequently allowed to hatch, and the spiderlings subjected to morphological and behavioral examination immediately after they had hatched.

Table 1. Distribution of D. raptor on the Hawaiian island of Kauai.

\begin{tabular}{rccccc}
\hline & $\begin{array}{c}\text { Wailua } \\
\text { River }\end{array}$ & $\begin{array}{c}\text { Hono O Na Pali } \\
\text { Waiahuakua }\end{array}$ & \multicolumn{2}{c}{$\begin{array}{c}\text { Mohihi-Wailae } \\
\text { Trail }\end{array}$} \\
\hline Elevation (m) & 390 & 390 & 390 & 1220 & 1220 \\
Date & 19-II-91 & 28-VII-90 & 16-II-91 & 23-VII-90 & 28-II-90 \\
Canopy Type & Metrosideros & Psidium/Pipturus & Metrosideros \\
Understory Type & Mixed Native & Psidium/Pipturus & Mixed Native \\
\hline Doryonychus raptor & & & & & \\
Number/hour & & & & & \\
Male & - & 8 & 6 & 0 & 0 \\
Female & - & 2 & 1 & 0 & 0 \\
Immature & - & 14 & 5 & 0 & 1 \\
Total collected & & 17 & 7 & 0 & 0 \\
Male & 0 & 6 & 1 & 0 & 0 \\
Female & 1 & 21 & 6 & 0 & 1 \\
Immature & 0 & & & & \\
\hline
\end{tabular}




\section{RESULTS}

Distribution: D. raptor was found at only 2 sites on Kauai (table 1):

(1) The Waiahuakua Valley in the Hono O Na Pali Natural Area Reserve at $390 \mathrm{~m}$. It is confined to a small area along the river directly beneath a $850 \mathrm{~m}$ waterfall that emanates from Mt. Waialeale, reputed to be the wettest place in the world. Much of this low elevation forest is disturbed, spiders being strongly associated with large-leaved tree species, the primary representatives in this area being the introduced guava, Psidium sp. (Myrtaceae) as well as the native mamake, Pipturus sp. (Urticaceae). The spiders are quite common here, although they appear to be much more abundant in the summer.

(2) A single immature individual was found in winter along the Mohihi-Waialae trail at $1220 \mathrm{~m}$. None have been found in this area during the summer.

In addition, a single mature female was accidentally collected (on plants) by Ken Wood of the National Tropical Botanical Gardens. This specimen was found directly below a $1000 \mathrm{~m}$ waterfall on the Wailua River at 390 m on east Kauai. This area is very similar to the Waiahuakua Valley site, and will likely yield more specimens in future surveys.

Ecological affinities: All observations were conducted in the Waiahuakua Valley site. Spiders here are strictly nocturnal, with daylight hours spent flat against the leaves. As a likely corollary to this behavior, the spiders are uniformly lime green over the entire body except for the venter, which is pearly white.

Foraging Behavior: During resting periods, the spider lies flat against a vertical substrate, the anterior end pointing down. Legs I, II and IV are held in a fairly typical tetragnathid posture, legs I and II stretched forward and IV backward. Unlike other tetragnathids, however, the metatarsus and tarsus of leg I diverge strongly, with the tarsal claws being well separated (Fig. 1 a). Also, the orientation of the third pair of legs, which are directed forward in a wide arc, is characteristic of this species. 
All spiders were found to be actively hunting during nocturnal field observations. Monitoring over 10-minute periods indicated that spiders spent most of the time (87\%) hanging upside down from silk threads using the third and fourth pairs of legs, with legs I and II held out free in front of the cephalothorax. The remainder of the time $(13 \%)$ was spent running actively around the vegetation.

The prey captures observed during cursorial foraging $(n=3)$ were all of cursorial insects, two homoptera and one orthopteran. Captures observed while the spider was hanging were all of small dipterans (sex unknown), either flying $(n=2)$ or hitting the substrate from which a spider was suspended $(n=4)$. The insects were captured using very rapid movements of one or more of the first two pairs of legs, but the precise mechanism of capture could not be determined in the field.

In the laboratory experiments using drosophilids of different sizes, feeding responses were observed for only 6 of the 10 spiders. Three spiders caught prey of all sizes, the other three of only two sizes. The results indicated that in all cases insects were captured using only the enlarged prolateral claws. In the case of small flies (D. simulans, $\mathrm{n}=4)$ only one long claw was used to both impale the insect and draw it up to the chelicerae, this occurring in a single, very rapid movement. Three of these insects were captured in the air during flight. In the case of larger flies (D. grimashawi, $\mathrm{n}=5$, and $D$. oahuensis, $\mathrm{n}=5$ ), the spider used both long claws on legs I ( $D$. grimashawi, $\mathrm{n}=4$, and D. oahuensis, $\mathrm{n}=2$ ), or else all 4 long claws on both legs I and II (D. grimashawi, $\mathrm{n}=1$, and D. oahuensis, $\mathrm{n}=4$ ). The movement in all cases was similar, the spider rapidly impaling the insect and drawing it up to the chelicerae in a single motion. Upon securing the prey with the fangs and chelicerae, the claws were immediately withdrawn. Insects were held and consumed in this manner without any wrapping. At intervals during feeding, the insect was moved around within the chelicerae, the manipulation being conducted by one of the long claws on either of the first pair of legs. Once the spider had finished feeding, prey were removed from the chelicerae using one tarsal claw of either of the first pair of legs. 

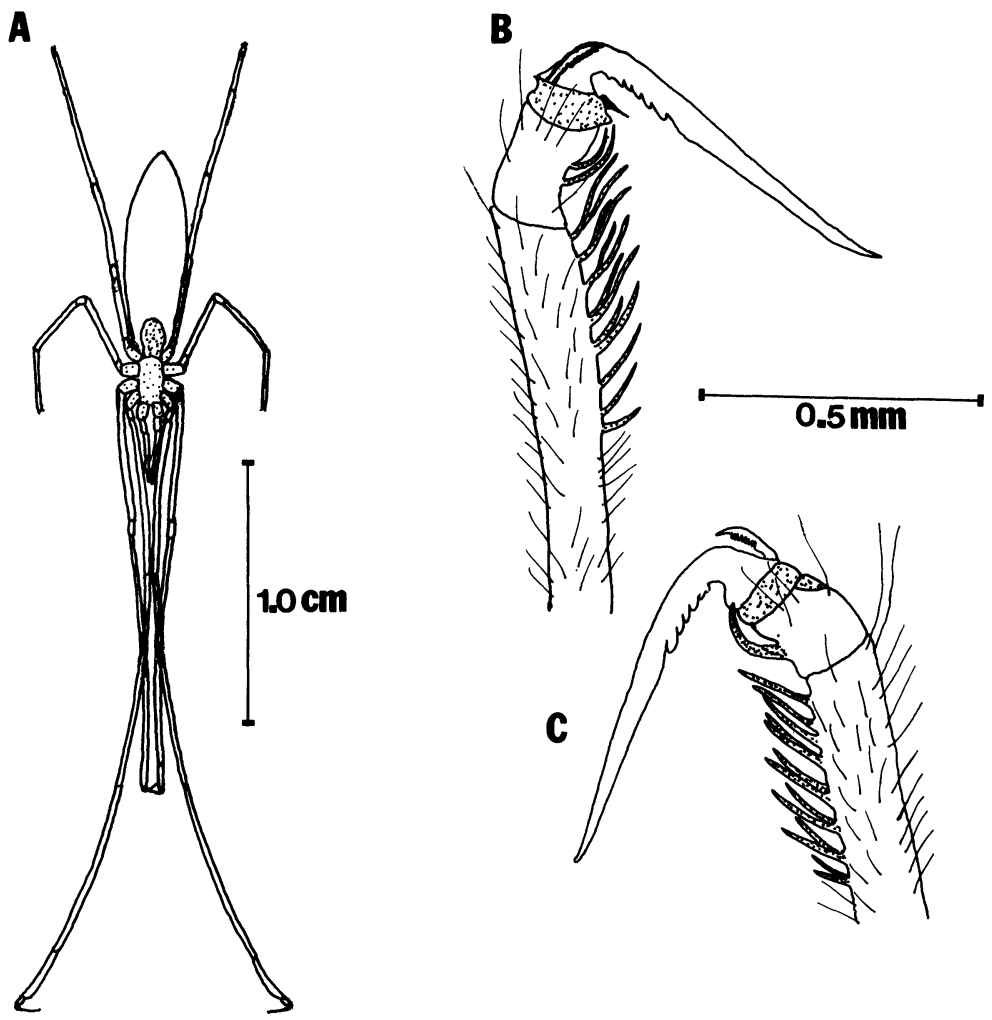

(Scale lines indicated; $b$ and $c$ drawn to same scale)

Figure $1 \mathrm{a}$. Ventral vew of the female $D$. raptor showing characteristic resting posture.

Figure $1 \mathrm{~b}$. Distal portion of the tarsus of a female D. raptor showing the onychium, strong macrotricheae and long prolateral claws. Posterior view.

Figure $1 \mathrm{c}$. Distal portion of the tarsus of a female $D$. raptor showing the onychium, strong macrotricheae and long prolateral claws. Anterior view. 
Motility on silk: When slightly disturbed during the first 3 days, D. raptor could maneuver successfully in the cage. After 5 days there was a considerable amount of prelaid silk in the cage, and it became progressively more difficult for the spiders to move around the cage, as the long claws of the first two pairs of legs were continually catching in the silk.

Morphology: One of the most prominent features of D. raptor is the extremely elongated prolateral claws on the tarsi of legs I and II. The retrolateral (Plate 1b) and medial (Plate $1 \mathrm{c}$ ) claws are both present and of normal proportions, although dwarfed by the prolateral claw (Fig. 1 b, c, Plate $1 \mathrm{a}, \mathrm{d}$ ). In males, the prolateral claw on leg $\mathrm{I}$ is $0.4-0.5 \mathrm{~mm}$ in length, $38-60 \%$ the length of the tarsus. In females, the same claw is $0.5-0.7 \mathrm{~mm}$ in length, $45-55 \%$ the length of the tarsus. All the claws are straighter than normal tetragnathid claws (Plate $1 \mathrm{f}$ ). The long prolateral claw is separated from a long onychium by a wide articulation (Fig. 1 b, c). The prolateral claw itself has a broad base, bending sharply over immediately above the base into a long, smooth projection (Plate $1 \mathrm{~d}$ ). Held within the sharp bend of the claw are 12-20 small serrations, approximately $10 \%$ the claw width; as the claw straightens, there are 5-6 similar but enlarged serrations, approximately 50\% the claw width. These serrations are set at an angle to the claw, giving a "corded" appearance.

Directly below the claw is the greatly enlarged onychium (Fig. $1 \mathrm{~b}$, c, Plate $1 \mathrm{~d}$ ). Strong macrotricheae line the ventral margin of onychium and the distal $2 / 3 \mathrm{rds}$ of the tarsus, these being directed up towards the base of the enlarged prolateral claw. A single

Plate 1 a. Ventral view of the right tarsus of leg I showing the elongated prolateral claw. $\times 100$. The retrolateral claw is outlined (magnified in Plate $1 \mathrm{~b}$ ).

Plate 1 b. Magnified view of the retrolateral claw outlined in Plate 1 a. $\times 500$.

Plate 1 c. Ventral view of the right tarsus of leg I showing the position and shape of the medial claw. $\times 1000$.

Plate $1 \mathrm{~d}$. Anterior view of the right tarsus of leg I showing the serrations in the bend of the elongated prolateral claw, the form of the macrotricheae, and the form of the retrolateral claw. $\times 300$.

Plate 1 e. Posterior lateral spinnerets, showing the absence of aggregate spigots. $\times 1000$.

Plate $1 \mathrm{f}$. The claws of Tetragnatha waikamoi Gillespie, showing the normal dimensions of the medial and pro- and retrolateral claws characteristic of tetragnathids. $\times 700$. 

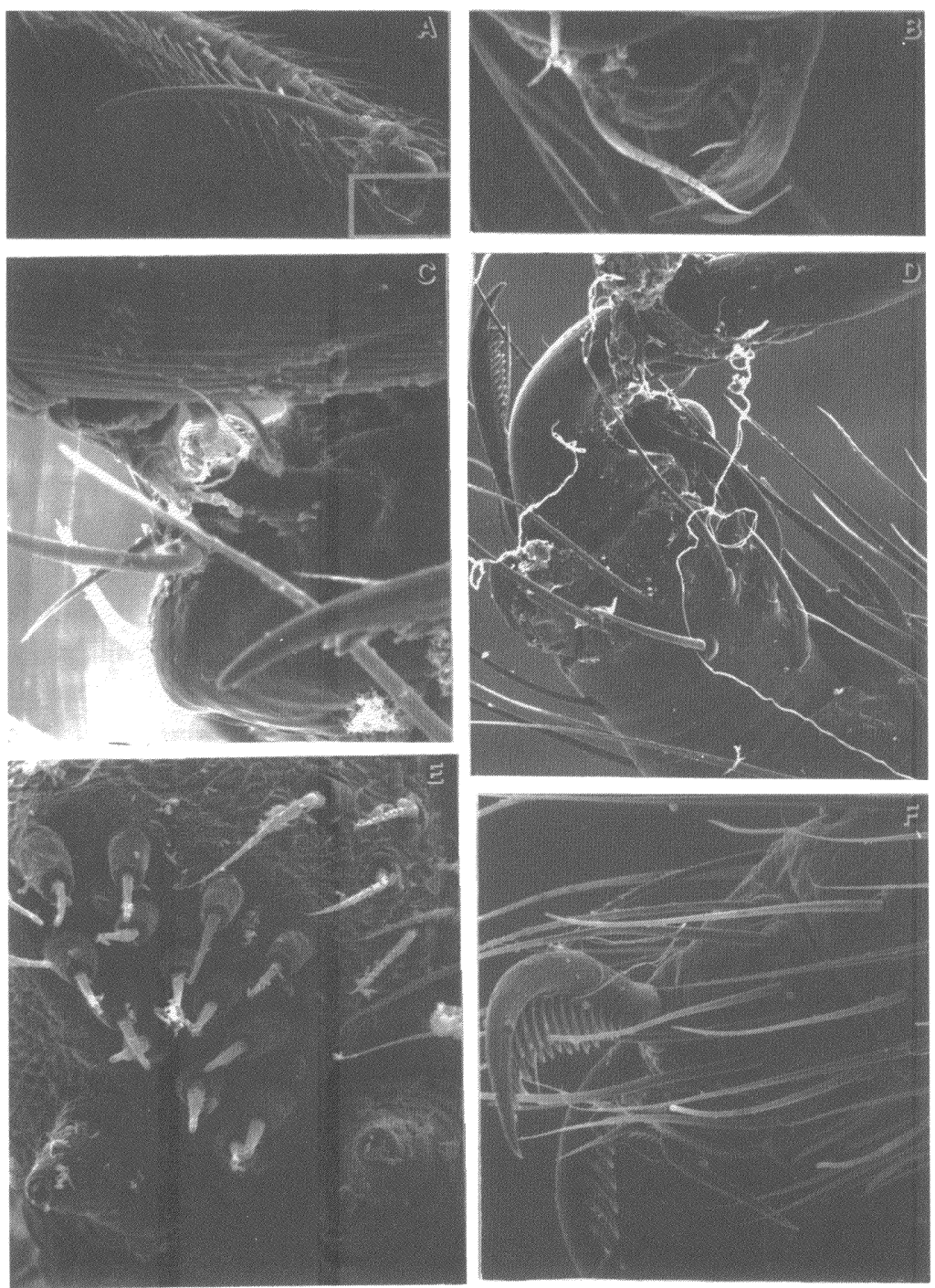
medial onychial macrotrichea is considerably stronger than all the others, and bends up and back into the area defined by the serrated bend of the enlarged claw (Plate $1 \mathrm{~d}$ ).

The most remarkable feature of the posterior lateral spinnerets is the complete absence of the aggregate glands, those normally associated with the production of sticky silk used in web-building (Plate $1 \mathrm{e}$ ).

Development: A total of 32 spiderlings were hatched from egg sacs. Spiderlings possess the greatly elongated prolateral claws on the first two pairs of legs even at the first instar. In addition, they do not build webs, and adopt a resting posture similar to that of the adult, with legs I and II stretched forward and IV backward, and the third pair of legs directed forward in a wide arc.

\section{Discussion}

This study reveals a unique foraging strategy hitherto undocumented in spiders. D. raptor has deviated radically from the characteristic behavior of the genus. It has completely abandoned web-building to become a cursorial, raptorial predator, the function of prey capture being virtually confined to the prolateral claws on the first two pairs of legs. It captures its prey by impaling them with one or more of these claws, depending on the size of the prey. Insects may be caught from the air while in flight, or else while walking on the substrate. The prolateral claws of the first two pairs of legs are highly modified for conducting predatory activity. They are very long, straight and articulated, the tarsus being provided with a double row of distally pointing robust macrotricheae. This behavior of capturing prey by impalement is apparent even during the earliest developmental stages. In addition, the complete absence of aggregate glands from the posterior spinnerets indicates a physiological inability to spin the characteristic tetragnathid orb. web.

Although this is the first documentation of prey impalement by spiders, the use of the tarsal region in prey capture is well known. A number of hunting spiders, for example, can use the adhesive scopular brush of hairs on the lower surface of the tarsus to facilitate grasping in the initial capture of prey (Rovner 1978). Subsequently, the prey is brought up into contact with the cheliceral fangs using the front legs (Melchers 1967, Rovner 1980). 
The remarkable set of morphological modifications characteristic of $D$. raptor-extreme and unequal elongation of the tarsal claws and the development of strong macrotricheae on the first 2 pairs of legs-has been documented in a number of groups, apparently having arisen independently in four quite unrelated lineages of spiders including D. raptor (Forster et al. 1987). Forward rotation of the third pair of legs may also be associated with this set of attributes, as, in addition to D. raptor, it is clearly evident in the gradungulid Spelungula cavernicola (Forster et al. 1987, Fig. 222).

Previous studies have been unable to ascertain the function of this set of modifications. The only species with claw elongation in which foraging behavior has been documented are the araneid Celaenia kinbergi (Stowe 1986, McKeown 1952) and the apparently primitive gradungulid Progradungula carraiensis (Forster et al. 1987). C. kinbergi appears to capture moths in its outstretched legs, with the function of the long claws unknown (Stowe 1986). $P$. carraiensis is confined to caves in Australia, where it builds a rather reduced web with a small catching platform from which it hangs in wait for its prey. The second, third and fourth legs support the spider on the web, while the first legs are held out in front of the body, the tarsal claws just touching the cave floor. The spider appears to feed primarily on rather large $(6-10 \mathrm{~mm})$ cursorial moths from the cave floor, using its raptorial legs in addition to its web when capturing moths. Based on these observations, Forster et al. (1987) speculated that claw elongation and modification of the tarsi of the first two pairs of legs has evolved as an adjunct to a specialized form of web-based prey capture. These observations could not, however, explain the tremendous elongation of a single claw on the first two pairs of legs. Also, the middle claw of the first two pairs of legs in P. carraiensis (Forster and Gray 1979, fig. 9), as in D. raptor (Plate 1 c), is vestigial and could not be used to hold the threads of a web, a conclusion corroborated by the tendency of D. raptor to become entangled in silk threads. It seems likely, therefore, that claw elongation evolved after the spider had abandoned web-building, or at least after the first two pairs of legs were released from their role in web activity. The present study is the first to clearly demonstrate how these long, spear-like claws can function as powerful weapons for impaling prey. 
It is remarkable that claw elongation appears to be confined to the prolateral claw on the first two pairs of legs in all four groups in which it occurs. The claw morphology of the third and fourth pairs of legs remains unchanged. Forward rotation of the third leg, however, as mentioned, appears to be associated with this suite of characters, and may allow the third pair of legs to serve as a brace while the spider captures prey with the first two pairs of legs. The precise nature of the morphological convergence in such disparate taxa suggests selection for a similar and highly specialized foraging mode. The evidence I have presented here implies that the primary function of the long claws is for impalement of prey. The presence of both a web and long claws in the cave-dwelling $P$. carraiensis may allow the spider to use alternative foraging strategies, and thereby maximize prey exploitation, in an environment where prey are likely to be scarce. The claws in $P$. carraiensis may be used primarily for impaling smaller, more agile prey, while the web is retained in order to allow the spider to secure larger prey.

The extremely specialized mode of foraging may underlie the very localized distribution of $D$. raptor. The species is almost entirely confined to lowland forests directly below high waterfalls emanating from Mt. Waialeale, and occurs only on a single Hawaiian island, Kauai. Lowland forests throughout the Hawaiian islands are highly susceptible to alien intrusion and anthropogenic disturbance; as a consequence, D. raptor is extremely vulnerable to extinction. The species therefore warrants listing as federally endangered in order to allow it some degree of protection.

\section{SUMMARY}

The genus Doryonychus (Araneae, Tetragnathidae) is endemic to small pockets of lowland forest on the Hawaiian island of Kauai. It is represented by a single species, D. raptor, which is characterized by a remarkable elongation of only the prolateral tarsal claws on the first two pairs of legs, and the development of a robust onychium lined with stout macrotricheae. I examined the foraging mode associated with this morphology. D. raptor has completely abandoned the web-building behavior characteristic of the genus, this being coupled with the loss of aggregate glands from the posterior spinnerets. Prey are captured, either in flight or from the substrate, by impalement with the claws, which occurs 
through a very rapid movement of one or more of the first two pairs of legs. The number of tarsal claws used to impale the prey varies according to the size of the prey, a single claw being used for very small diptera (the most common prey item), all four claws being used for larger insects.

\section{ACKNOWLEDGEMENTS}

This study was supported by a grant from the Hawaii Natural Area Reserves System, with additional funding from the Hawaii Bishop Research Institute and the Nature Conservancy of Hawaii. Support was also provided by the Bishop Museum and the Zoology Department, U. H. Manoa. I am deeply indebted to Chris Parrish, David Preston and George Roderick for their assistance in collecting specimens in remote areas where access was difficult. Thanks also to Ken Wood for the specimen of D. raptor from the Blue Hole, and to David Lorence and Steve Perlman for logistical support. Kenneth Kaneshiro allowed me to use his environmentally controlled facilities to maintain and rear live specimens. Thanks also to Marilyn Dunlap and Tina Carvalho for help with the SEM. Also to Stephen Palumbi, Herbert Levi and Jonathan Coddington for advice and discussion and to Dan Polhemus for comments on the first draft of the manuscript.

\section{Literature Cited}

CARICO, J. E.

1978. Predatory behavior in Euryopis funebris (Hentz) (Araneae: Theridiidae) and the evolutionary significance of web reduction. Symp Zool Soc London 42: 51-5.

DABRowsKa PRot, E. AND J. LuCZAK

1968. a. Spiders and mosquitos of the ecotone alder forest (Carici elongatae-alnetum) and oak pine forest (Pino quercetum). Ekologia Polska Seria A. XVI (22): 461-483.

b. Studies on the incidence of mosquitos in the food of Tetragnatha montana Simon and its food activity in the natural habitat. Ekologia Polska Seria A. XVI (43): 843-853.

Dabrowska Prot, E., LuCZaK, J. AND Tarwid, K.

1968. Prey and predator density and their reactions in the process of mosquito reduction by spiders in field experiments. Ekologia Polska Seria A. XVI (40): 773-819.

FORSTER, R. R. AND GRAY, M. R.

1979. Progradungula, a new cribellate genus of the spider family Gradungulidae (Araneae). Aust. J. Zool. 27: 1051-1071. 
Forster, R. R., Platnick, N. I. And Gray, M. R.

1987. A review of the spider superfamilies Hypochiloidea and Austrochiloidea (Araneae, Araneomorphae). Bull. Am. Mus. Nat Hist. 185: $1-116$.

GILLESPIE, R. G.

1986. Between population comparison of resource acquisition in the long jawed orb weaving spider Tetragnatha elongata. PhD dissertation, University of Tennessee, Knoxville, TN.

1987. The mechanism of habitat selection in the long jawed orb weaving spider Tetragnatha elongata (Araneae, Tetragnathidae). J. Arachnol. 15: 81-90.

1991. Hawaiian Spiders of the Genus Tetragnatha: I. Spiny Leg Clade. in press. J. Arachnol.

1992. Hawaiian Spiders of the Genus Tetragnatha II. Species from natural LEVI, H. W. areas of windward, East Maui. J. Arachnol. in press.

1981. The American orb-weaver genus Dolichognatha and Tetragnatha north of Mexico (Araneae: Araneidae, Tetragnathinae). Bull. Mus. Comp. Zool. Harvard. 149(5): 271-318.

McKeown, K. C.

1952. Australian Spiders. Angus and Robertson, Sydney.

Melchers, M.

1967. Der Beutefang von Cupiennius salei Keyserling (Ctenidae). Z. Morph. Ökol. Tiere 58: 321-346.

Platnick, N. I.

1976. Notes on the spider genus Doliomalus (Araneae, Gnaphosoidea). Rev. Zool. Africaine. 90 (4): 975-983.

RoBINSON, M. H.

1982. The ecology and biogeography of spiders in Papua New Guinea. Monogr. Biol. 42: 557-581.

ROVNER, J. S.

1978. Adhesive hairs in spiders: Behavioral functions and hydraulically mediated movement. Symp. Zool. Soc. Lond. 42: 99-107.

1980. Morphological and ethological adaptations for prey capture in wolf spiders (Araneae: Lycosidae). J. Arachnol. 8: 201-216.

SimON, E.

1900. Arachnida: Fauna Hawaiiensis 2(5): 443-519, pls. 15-19.

STOWE, M. K.

1978. Observations of two nocturnal orbweavers that build specialized webs: Scoloderus cordatus and Wixia ectypa (Araneae: Araneidae). J. Arachnol. 6: 141-146.

1986. Prey specialization in the Araneidae. In: Shear WA (ed) Spiders: webs, behavior, and evolution. Stanford Univ Press, Stanford, Calif, pp 101-131.

WIEHLE, $\mathrm{H}$.

1963. Tetragnathidae. Tierwelt Deutschlands. 49: 1-76.

YoshIDA, M.

1987. Predatory behavior of Tetragnatha praedonia (Araneae: Tetragnathidae). Acta Arachnologica 35(2): 57-75. 

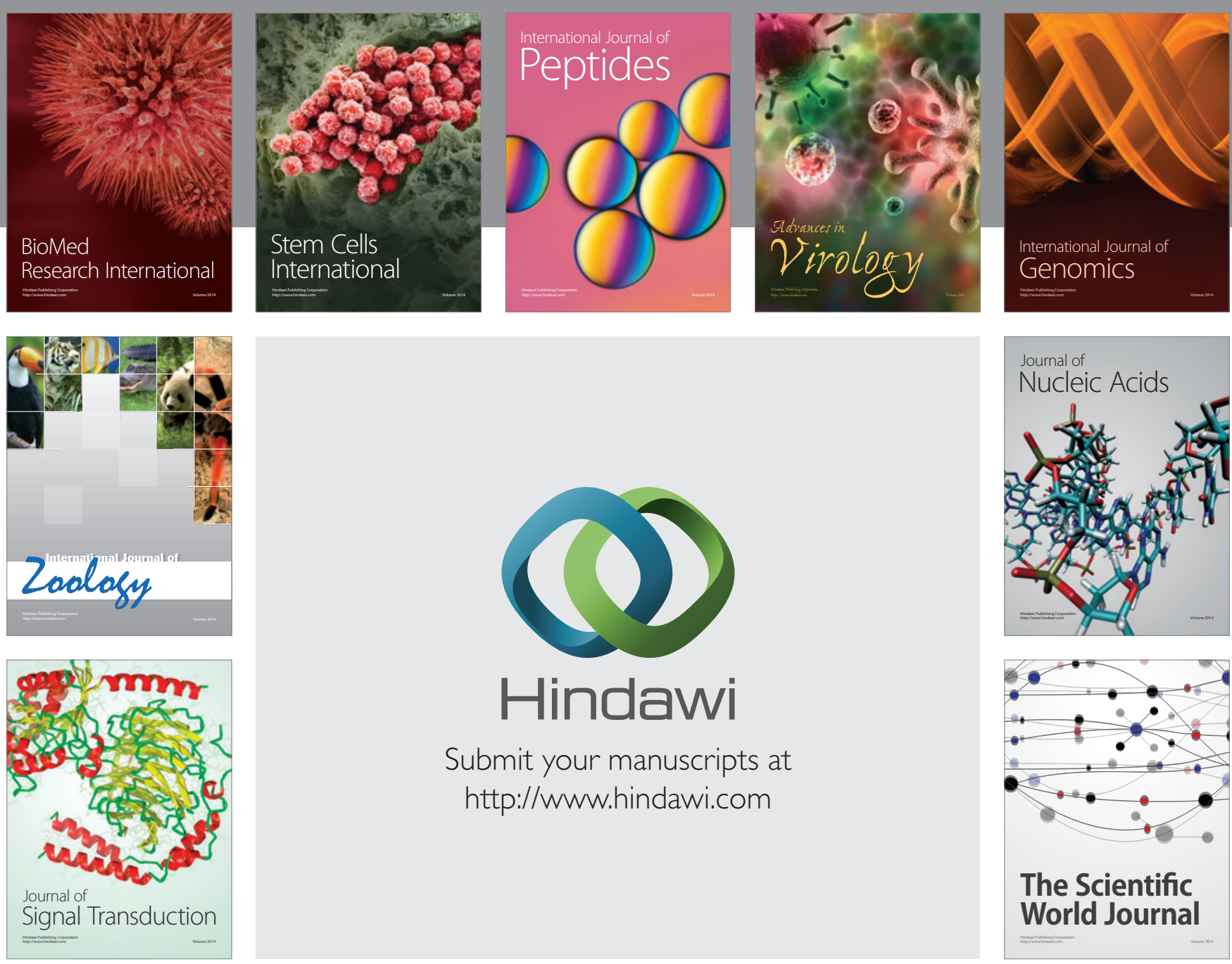

Submit your manuscripts at

http://www.hindawi.com
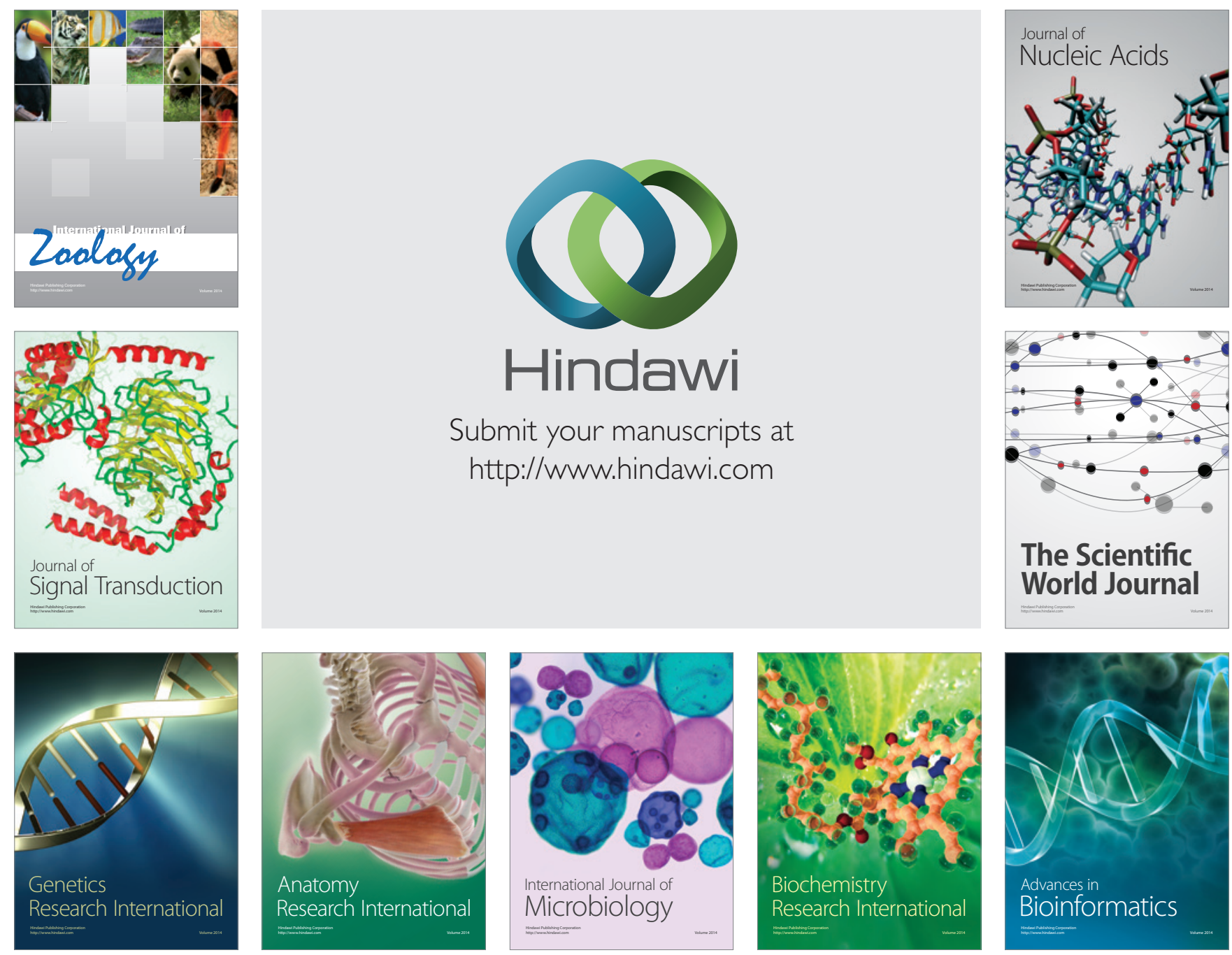

The Scientific World Journal
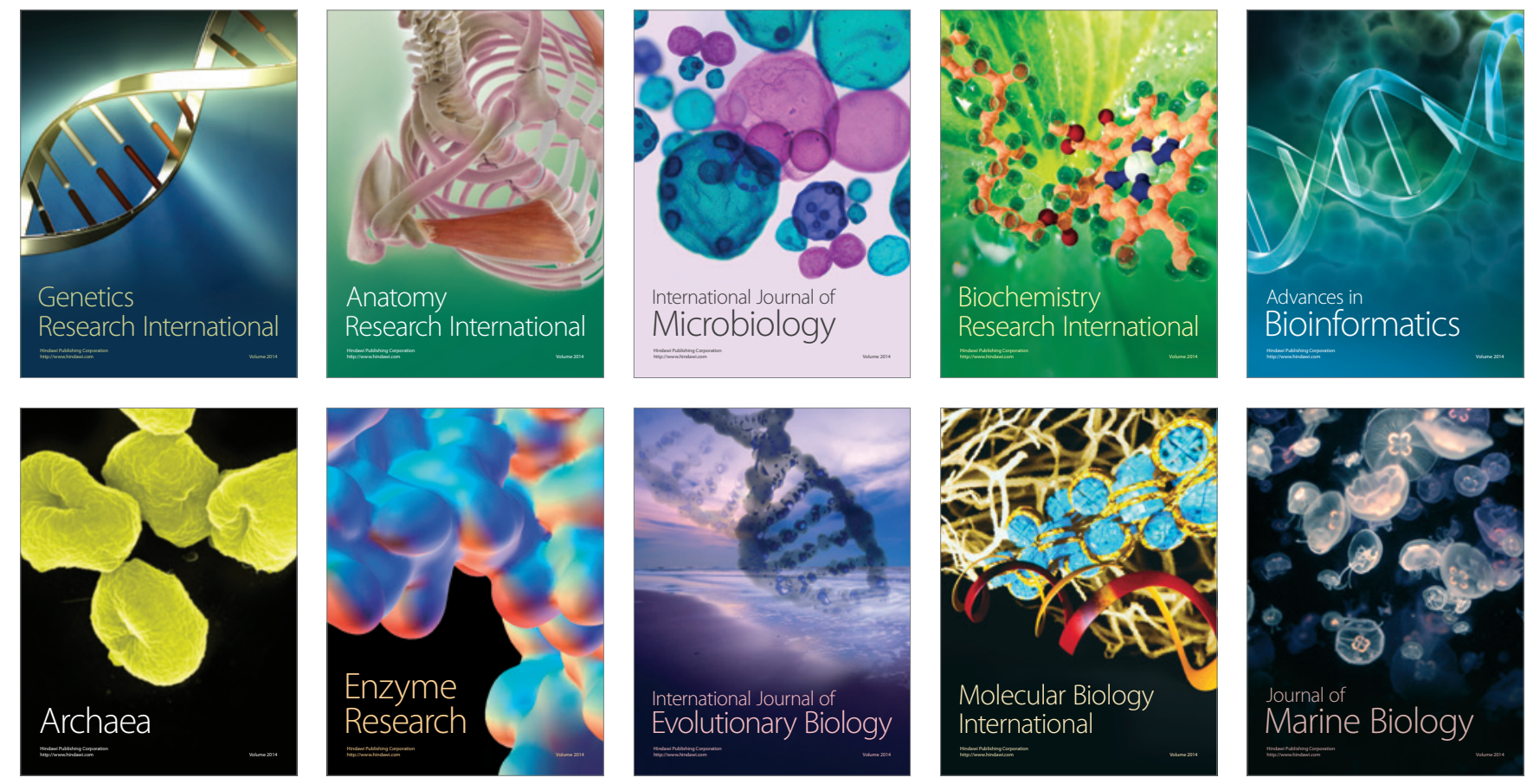